\title{
Physical and Engineering Properties of Turmeric Fingers
}

\author{
D. V. Nimbalkar ${ }^{1 *}$, S. M. Nalawade ${ }^{2}$, S. C. Bhangare ${ }^{2}$, \\ A. A. Walunj ${ }^{3}$ and C. A. Nimbalkar ${ }^{4}$ \\ ${ }^{1}$ Department of Agricultural engineering and Technology, ${ }^{2}$ Department of Farm Machinery \\ and Power Engineering, CAET, ${ }^{3}$ Department of Mechanical Engineering, Dr. A.S.C.A.E. \& T, \\ ${ }^{4}$ Department of Statistics, MPKV, Rahuri, India \\ *Corresponding author
}

Keywords

Physical Properties of Turmeric fingers, Angle of repose, Geometric Property, Coefficient of Friction, Turmeric fingers, etc

Article Info

Accepted:

22 April 2021

Available Online:

10 May 2021

\section{A B S T R A C T}

Turmeric (Curcuma longa) fingers (Salem) sample was divided into three grades (I: $30-40 \mathrm{~mm}$, II: $40-50 \mathrm{~mm}$ and III: $50-60 \mathrm{~mm}$ ) according to its major dimension to study physical properties. Geometric properties viz., length, breath, thickness, arithmetic mean diameter, geometric mean diameter, square mean diameter, equivalent diameter, sphericity, aspect ratio, unit volume, surface area and shape factor were determined and found to be in the range of $30.18-48.54 \mathrm{~mm}, 9.72-10.62 \mathrm{~mm}, 5.12-6.38 \mathrm{~mm}, 14.72-$ $22.84 \mathrm{~mm}, 12.72-14.64 \mathrm{~mm}, 23.21-26.54 \mathrm{~mm}, 0.24-0.38,0.18-0.32,1591-$ $2904 \mathrm{~mm}^{3} 772-1268 \mathrm{~mm}^{2}$ and 1.61-1.74 for Grade I, II and III respectively. The gravimetric and frictional properties such as bulk density, true density, porosity and angle of repose were $264-348 \mathrm{~kg} / \mathrm{m}^{3}, 1340-1358 \mathrm{~kg} / \mathrm{m}^{3}, 72.51-$ $78.90 \%$ and $35.57-37.90^{\circ}$, respectively. Also, coefficient of friction with surfaces namely plywood sheet were found to be in the range $0.82-0.88$, respectively. The results of the study will help in designing the feed hoppers, metering mechanisms and planting equipment.

\section{Introduction}

Spices are valued for their distinctive flavours, colours and aromas and are among the most versatile and widely used ingredients in food preparation and processing throughout the world. The fingers of the Turmeric plant (Curcuma longa L.), is a tropical herb of the Zingiberaceae family native to southern
Asia has a traditionally important role as a colouring component. It is widely used as a spice and common food and additive (Govindarajan, 1980). Curcumin (Diferuloyl methane), the main yellow coloured bioactive component of turmeric has been shown to have a broad spectrum of biological actions. The determination of physical properties of agricultural materials is important to design 
machines and processes conveying, for designing feed hoppers and metering mechanisms and storage of these materials and requires understanding for converting these materials into food and feed. For agricultural materials, dimensions (length, diameter, thickness) are widely used to describe them.

Fingers physical dimension, particularly shape, is very important in sorting and sizing, and determines how many Fingers can be placed in shipping containers or plastic bags of a given size (Keramat-Jahromi et al., 2008).

Fingers skin color is an attribute that determines consumer's behavior and it is accepted as one of the most important external quality parameters (Ercisli et al., 2007). Fingers volume, shape and density are important to design fluid velocities for transportation (Mohsenin, 1986).

On the other hand, knowledge of frictional properties of Fingers is needed for the design of planting and handling equipment (Mohsenin, 1986).

\section{Materials and Methods}

$20 \mathrm{~kg}$ of fresh Turmeric Fingers from the Yavatmal District Market were purchased to measure the properties. The physical properties determined for Turmeric Fingers were size, shape, bulk density, true density, porosity, the angle of repose, surface area and coefficient of friction. The methods adopted for estimating these parameters are given below.

\section{Dimensions of Turmeric Fingers}

Turmeric Finger was randomly chosen for measuring dimensions. Length, width and thickness of each Finger were measured using vernier caliper (least count $0.01 \mathrm{~cm}$ ). A Hundred observations were made to get average values of length, width and thickness of the Turmeric Rhizome.

\section{Geometric Mean Diameter (GMD)}

The geometric mean diameter for the 100 fingers was determined using the measured geometric dimensions of length (L), width (W) and thickness (T) (Mohsenin, 1986). The equation is given below.

$$
G M D=(L W T)^{\frac{1}{3}}(1)
$$

\section{Sphericity}

Sphericity (S) is defined as the ratio of the surface area of a sphere having the same volume as the Finger to the surface area of the Rhizome.

The shape of a food material is usually expressed in terms of its sphericity. It is an important property used in fluid flow and heat and mass transfer calculations. Sphericity was determined using the measured geometric dimensions (Eqn 2).

$$
S=\frac{(L W T)^{\frac{1}{3}}}{L}(2)
$$

In order to gather more information about the shape of the Rhizome, aspect ratio (R) of the Finger was determined using the following relationship.

\section{Kernel Weight (TKW)}

The mass of 100 Rhizomes weighed on a top loading electronic balance (EK 5350) with a resolution of $0.01 \mathrm{~g}$ and the resultant weight was multiplied by 10 to get the 1000 fingers weight. This method was used by Tavakoli et al., (2009) for barley grains and Gharibzahedi et al., (2010) for pine nut. 


\section{Surface Area and Volume}

The surface area and volume of Turmeric Finger were calculated based on the geometric mean diameter (GMD) in the following equations.

$$
\begin{aligned}
& S=\pi(G M D)^{2}(4) \\
& V=\frac{\pi}{6}(G M D)^{3}(5)
\end{aligned}
$$

\section{Radius of Curvature}

This is an important property required for the design of conveyors and chutes. It determines the rollability of objects. The minimum radius of curvature (Rmin) and maximum radius of curvature (Rmax) was calculated using the followings equations

$$
\begin{gathered}
R_{\min }=\frac{H}{2}(6) \\
R_{\max }=\frac{H^{2}+\frac{L^{2}}{4}}{2}(7)
\end{gathered}
$$

\section{Angle of Repose}

The angle of repose is an important physical property for the design of processing, storage and conveying systems of particulate materials. When the material is smooth and rounded, the angle of repose is low. For sticky and fine materials the angle of repose is high. The angle of repose, therefore, indicates the cohesion amongst the individual units of the materials. It was determined using a bottomless cylinder $(10 \mathrm{~cm}$ diameter and 15 $\mathrm{cm}$ height) which was also applied by Taser et al., (2005). The cylinder was placed on a smooth surface and turmeric Finger were filled in. The cylinder was raised slowly permitting the sample to flow down and form a natural slope. The height $(\mathrm{H})$ and diameter (D) of the heap were measured and the dynamic angle of repose was calculated by Eq 8.

$$
\theta=\tan ^{-1} \frac{2 H}{D}(8)
$$

\section{Bulk Density}

Bulk density which is defined as the ratio of the mass of the sample to its container volume was evaluated by weighing a Turmeric Finger filled beaker of known weight and volume and calculated as Baryeh (2000). Where $\rho b$ $(\mathrm{g} / \mathrm{cm} 3)$ is bulk density and $\mathrm{m}$ is mass $(\mathrm{g})$ of the sample.

$$
\rho_{b=} \frac{\text { Mass }}{\text { Volume }}=\frac{m}{v}(9)
$$

\section{True Density}

It is the ratio of the mass of the sample to its true volume. For Turmeric finger, true density was determined by the water displacement method (Abdullah, 2011). The true density was calculated using following equation:

$$
\rho_{t=} \frac{\text { Massofindividualf ruit }(\mathrm{kg})}{\text { Volumeofindividualseed }\left(\mathrm{m}^{3}\right)}(10)
$$

\section{Porosity}

Porosity is a vital physical property that characterizes the amount of air spaces in a bulk. It is needed in modeling and design of various hoppers. It is defined as the volume fraction of air in the bulk sample and is calculated by Eqn 11:

$$
\text { Porosity, } P=\frac{\rho_{t-} \rho_{b}}{\rho_{t}} \times 100(11)
$$


Table.1 Physical Properties of Turmeric Finger

\begin{tabular}{|c|c|c|c|}
\hline \multicolumn{4}{|c|}{ Geometnc property } \\
\hline Length $(\mathrm{mm})$ & $34.38 \pm 1.42$ & $44.42 \pm 1.76$ & $52.60 \pm 4.76$ \\
\hline Breadth (mm) & $12.64 \pm 0.64$ & $9.62 \pm 1.08$ & $9.94 \pm 2.68$ \\
\hline Thickness (mm) & $7.44 \pm 1.71$ & $6.46 \pm 1.83$ & $5.18 \pm 1.60$ \\
\hline Arithmetic mean diameter (mm) & $13.82 \pm 0.75$ & $15.50 \pm 1.12$ & $21.91 \pm 1.33$ \\
\hline Sphericity & $0.32 \pm 0.04$ & $0.34 \pm 0.07$ & $0.27 \pm 0.04$ \\
\hline Aspect ratio & $0.36 \pm 0.06$ & $0.25 \pm 0.02$ & $0.20 \pm 0.03$ \\
\hline Unit volume (mm²) & $1647 \pm 20.12$ & $2118 \pm 49.27$ & $2901 \pm 31.42$ \\
\hline Surface area $\left(\mathrm{mm}^{2}\right)$ & $775 \pm 15.11$ & $970 \pm 17.31$ & $1265 \pm 27.92$ \\
\hline Shape factor & $1.73 \pm 0.14$ & $1.50 \pm 0.27$ & $1.66 \pm 0.22$ \\
\hline \multicolumn{4}{|c|}{ Gravimetric property } \\
\hline Bulk density $\left(\mathrm{kg} / \mathrm{m}^{3}\right)$ & $343 \pm 6.34$ & $282 \pm 7.94$ & $260 \pm 5.11$ \\
\hline True density $\left(\mathrm{kg} / \mathrm{m}^{3}\right)$ & $1352 \pm 7.86$ & $1338 \pm 6.80$ & $1349 \pm 5.47$ \\
\hline Porosity (\%) & $74.56 \pm 0.62$ & $74.71 \pm 0.21$ & $80.93 \pm 0.42$ \\
\hline \multicolumn{4}{|c|}{ Frictional property } \\
\hline Angle of Repose (0) & $37.52 \pm 0.62$ & $34.32 \pm 0.19$ & $38.90 \pm 0.23$ \\
\hline \multicolumn{4}{|c|}{ Coefficient of friction } \\
\hline Plywood sheet & $0.86 \pm 0.08$ & $0.96 \pm 0.04$ & $0.80 \pm 0.06$ \\
\hline
\end{tabular}

Table.2 Symbols

\begin{tabular}{|c|c|c|c|}
\hline $\mathrm{L}$ & major diameter with calyx (mm) & 11 & $\rho$, bulk density $\left(\mathrm{g} / \mathrm{cm}^{3}\right)$ \\
\hline W & intermediate diameter $(\mathrm{mm})$ & 12 & E Porosity \\
\hline $\mathrm{T}$ & minor diameter $(\mathrm{mm})$ & 13 & "t true density $\left(\mathrm{g} / \mathrm{cm}^{3}\right)$ \\
\hline $\mathrm{CPA}$ & criteria projectedarea $\left(\mathrm{mm}^{2}\right)$ & 14 & $\Phi$ sphericity \\
\hline $\mathrm{R}^{2}$ & coefficient of detemination & 15 & $\varphi$ angle of repose (degree) \\
\hline Dg & geometric mean diameter $(\mathrm{mm})$ & 16 & ${ } \mathrm{~s}$ static coefficient of friction \\
\hline $\mathrm{M}$ & $\operatorname{mass}(\mathrm{g})$ & 17 & $\mathrm{~W}_{\text {tooo }}$ thousandseeds mass (g) \\
\hline PA1 & first projected area $\left(\mathrm{mm}^{2}\right)$ & 18 & Yosp $\left(\mathrm{cm}^{3}\right)$ \\
\hline $\mathrm{PA} 2$ & second projected area $\left(\mathrm{mm}^{2}\right)$ & 19 & Vvolume $\left(\mathrm{cm}^{3}\right)$ \\
\hline $\mathrm{PA} 3$ & third projected area $\left(\mathrm{mm}^{2}\right)$ & 20 & Ysp volume of ellipsoid $\left(\mathrm{cm}^{3}\right)$ \\
\hline
\end{tabular}


Fig.1
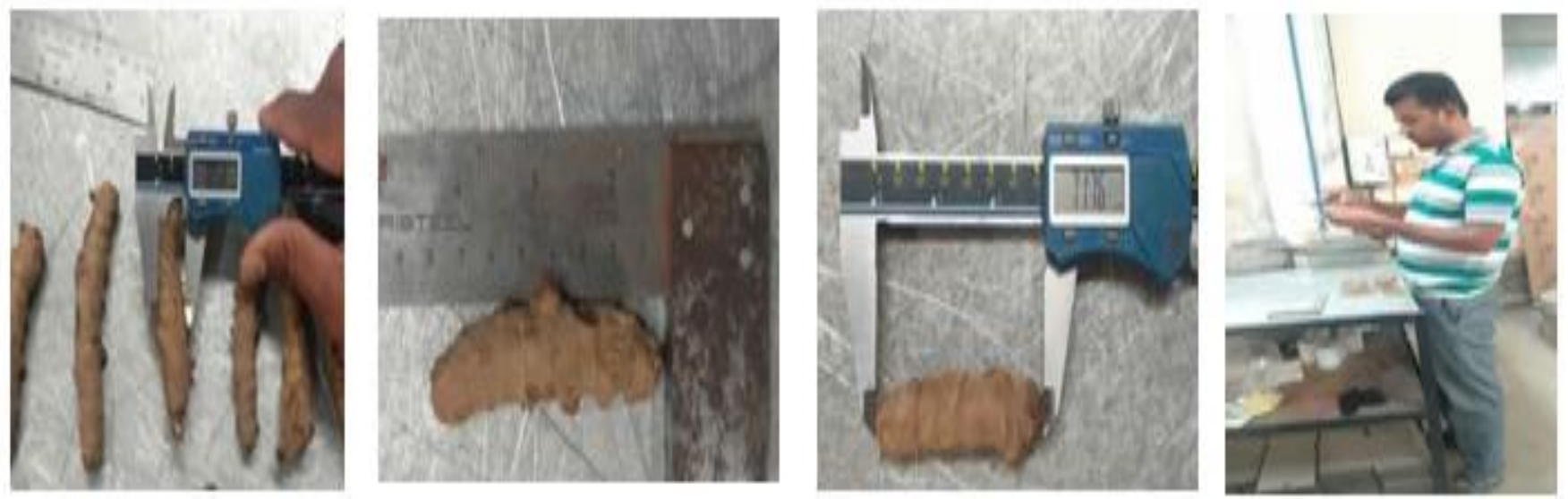

\section{Coefficient of Static Friction}

This is the ratio of force needed to start sliding the sample over a surface by the weight of the sample. The coefficient of static friction was determined on wood surfaces, namely plywood, Each Finger was placed on the surface and raised gradually by screw until the Finger begin to slide. The angle $\theta$ of the inclined surface with the horizontal platform at the beginning of the sliding was measured. The coefficient of static friction $(\mu \mathrm{s})$ was calculate using the following equation.

$$
\mu_{s}=\tan \theta(12)
$$

\section{Results and Discussion}

The physical properties of Turmeric Fingers are given in Table 1. The average length of three grades was $30.38 \mathrm{~mm}, 40.57 \mathrm{~mm}$ and $50.60 \mathrm{~mm}$. However, there is no trend for breadth $(10.64 \mathrm{~mm}, 9.72 \mathrm{~mm}$ and $9.94 \mathrm{~mm})$ and thickness $(6.44 \mathrm{~mm}, 5.47 \mathrm{~mm}$ and 5.18 $\mathrm{mm}$ ) among different grades. The sphericity, aspect ratio and shape factor of turmeric fingers decreased with increase in dimension. This may be attributed to the irregular shape of turmeric fingers. The unit volume and surface area of turmeric rhizomes showed a linear relationship with grade size. The angle of repose increased with respect to grades (dimension) i.e. $37.570,38.440$ and $38.90^{\circ}$ for grade I, II and III respectively. The coefficient of friction with respect to these grades on different structural surface viz., plywood sheet $(0.86-0.80)$ is depicted in Table 1.

The physical properties measured can be very useful for designing and development of turmeric planting machine, feed hoppers, booth structure and other purposes.

\section{References}

Abdullah M R, Chng P E and Lim T H (2011). Some physical properties of Parkia speciosa seeds. International Conference on Food Engineering and Biotechnology, IPCBEE, IACSITPress, Singapore.

Al-Maiman S A and Ahmad D (2002). Changes in physical and chemical properties during Turmeric Fingers (Punica granatum L.) fingers maturation. Food Chemistry, 76: 437-441.

Aydin C (2002). Physical properties of hazelnuts. Biosystem Engineering, 82: 297-303.

Aydin C (2003). Physical properties of almond nut and kernel. Journal of Food Engineering, 60: 315-320. 
Bart-Plange A and Baryeh E A (2003). The physical properties of category B cocoa beans. Journal of Food Engineering, 60: 219-227.

Baryeh E A (2001). Physical properties of Bambara groundnuts. Journal of Food Engineering, 47: 321-326.

Celik A and Ercisli S (2008). Persimmon cv. Hachiya (Diospyroskaki Thunb.) fingers: some physical, chemical and nutritional properties. International Journal of Food Science and Nutrition, 59(7): 599-606.

Celik A, Ercisli S and Turgut N (2007). Some physical, pomo-logical and nutritional properties of kiwi Fingers cv. Hayward. International Journal of Food Science and Nutrition, 58: 411-418.

Dursun E and Dursun I (2005). Some physical properties of caperseed. Biosystem Engineering, 92(2): 237-245. Ercan N, Ozvardar S, Gonulsen N, Baldiran E, Onal $\mathrm{K}$ and

Karabiyik N (1992). Determination of suitable Turmeric Fingers cultivars for Aegean region (in Turkish). Proceeding of

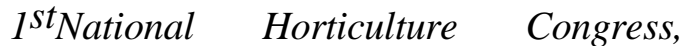
October 13-16, Izmir, Turkey.

Ercisli S (2004). A short review of the Fingers germplasm resources of Turkey. Genetic Resources and Crop Evolution, 51: 419435.

Ercisli S, Orhan E, Ozdemir O and Sengul M (2007). The genotypic effects on the chemical composition and antioxidant activity of sea buckthorn (Hippophae rhamnoides L.) berries grown in Turkey. Scientia Hoticulturae, 115(1): 27-33.

Fadavi A, Barzegar M, Azizi M H and Bayat M (2005). Physicochemical composition of ten Turmeric Fingers cultivars (Punica granatum L.) grown in Iran. Food Science and Technology International, 11: 113-119.

Fathollahzadeh H and Rajabipour A (2008). Some mechanical properties of barberry. International Agrophysics, 22: 299-302. Ghasemi-Varnamkhasti M, Mobli H, Jafari A, Keyhani AR, Heidari-
Soltanabadi M, Rafiee S and Kheiralipour K (2008).

Some physical properties of rough rice (Oryza Sativa L.) grain. Journal of Cereal Science, 47: 496- 501.

Jain R K and Bal S (1997). Properties of pearl millet. Journal of Agricultural Engineering Research, 66: 85-91.

Kabas O, Ozmerzi A and Akinci I (2006). Physical properties of cactus pear (Opuntia ficusindica L.). Journal of Food Engineering, 73: 198-202.

Kazankaya A, Gundogdu M, Askin M A and Muradoglu F (2003). Fingers attributes of local Turmeric Fingers grown in Pervari (in Turkish). Proceeding of $4^{\text {th }}$ National Horticulture Congress, September 8-12, Antalya, Turkey.

Keramat-Jahromi M, Rafiee S, Jafari A, Ghasemi BMR, Mirasheh $\mathrm{R}$ and Mohtasebi SS (2008). Some physical properties of date Fingers (cv. Dairi). International Agro Physics, 22: 221-224.

Kingsly A R P, Singh D B, Manikantan M R and Jain R K(2006). Moisture dependent physical properties of dried pomegranate seeds (Anardana). Journal of Food Engineering, 75: 492-496.

Lorestani A N and Tabatabaeefar A (2006). Modeling the mass of Kiwi Fingers by geometrical attributes. International Agro Physics, 20: 135-139.

Mars M (1996). Turmeric Fingers genetic resources in the Medi-taerranean region. Proceeding of $1^{\text {st }}$ MESFIN Plant Genetic Resources Meeting, October 2-4, Tenerife, Spain.

Marvin J P, Hyde G M and Cavalieri R P (1987). Modeling potato tuber mass with tuber dimensions. Transaction of ASAE,30: 1154-1159.

Meisami-as 1 E, Rafiee S, Keyhani A and Tabatabaeefar A (2009). Some Physical Properties of Apple cv. 'Golab'. Agricultural Engineering International: the CIGR Ejournal. Vol. XI, March 2009.

Mirzaee E, Rafiee S, Keyhani AR, Emamjomeh $\mathrm{Z}$ and Kheiralipour K (2008). Mass 
modeling of two varieties of apricot (Prunus armenaica L.) with some physical characteristics. Journal of Plant Omics, 1: 37-43.

Mohsenin N N (1986). Physical properties of plant and animal materials. Gorden and Breach Science Publishers, New York, USA.

Nimkar MP and Chattopadhyay KP (2001). Some physical properties of green gram. Journal of Agricultural Engineering Research, 80: 183-189.

Ozguven F and Vursavus K (2005). Some physical, mechanical and aerodynamic properties of pine (Pinuspinea) nuts. Journal of Food Engineering, 68: 191196.

Ozkan Y (2005). Investigations on physical and chemical characteristics of some Turmeric Fingers genotypes (Punica granatum L.) of Tokat province in Turkey. Asian Journal of Chemistry, 17: 939-942.

Paksoy M and Aydin C (2004). Some physical properties of edible squash seeds. Journal of Food Engineering, 65: 225-231. Perkins-Veazie P (1992). Physiological changes during ripening of raspberry Fingers. Horticulture Science, 27: 331333.

Poyrazoglu E, Gokmen V and Artik N (2002). Organic acidsand phenolic compounds in Turmeric Fingers (Punica granatum L.) grown in Turkey. Journal of Food Composition and Analysis, 15: 567-575.

Tavakoli M, Tavakoli H and Ahmadi H (2009) Moisture- dependent physical properties of barley grains. International Journal of Agricultural and Biological Engineering, 2: 341-350.

Taser O F, Altuntas E and Ozgoz E (2005). Physical properties of Hungarian and vommon vetch seeds. Journal of Applied Science, 5: 323-326.

Gharibzahedi S, Etemad V and Foshat M (2010). Moisture dependent engineering properties of black cumin seed.

Agricultural Engineering International: CIGR, 12(1): 194-202.

Tibet $\mathrm{H}$ and Onur C (1999). Adaptation of Turmeric Fingers (Punica granatum L.) cultivars in Antalya region (in Turkish).Proceeding of 3th National Horticulture Congress, September 14-17, Ankara, Turkey.

Topuz A, Topakci M, Canakci M, Akinci I and Ozdemir F (2005). Physical and nutritional properties of four Turmeric Fingers varieties. Journal of Food Engineering, 66: 519-523.

Vursavus K, Kelebek H and Selli S (2006). A study on some chemical and physicomechanic properties of three sweet cherry va-rieties (Prunu savium L.) in Turkey. Journal of Food Engineering, 74: 568-575.

Yilmaz H, Sen B and Yildiz A (1992). Regional adaptation of Turmeric Fingers selected from Mediterranean region (in Turkish). Proceeding of $1^{\text {st }}$ National Horticulture Congress, October 13-16, Izmir, Turkey.

\section{How to cite this article:}

Nimbalkar, D. V., S. M. Nalawade, S. C. Bhangare, A. A. Walunj and Nimbalkar, C. A. 2021. Physical and Engineering Properties of Turmeric Fingers. Int.J.Curr.Microbiol.App.Sci. 10(05): 777-783. doi: https://doi.org/10.20546/ijcmas.2021.1005.088 